\title{
Viver na baia: dimensões psicossociais da saúde e do controle no trabalho de teleatendimento
}

\author{
Carolina Calmon Ramalho, \\ Felipe Augusto de Azevedo Marques Arruda, \\ Leny Sato e Luana Flor Tavares Hamilton
}

Instituto de Psicologia da Universidade de São Paulo

\begin{abstract}
O objetivo desse artigo é estudar como operadores de teleatendimento vivenciam o trabalho em sua relação com a saúde. O estudo empírico consistiu em visita a uma empresa de teleatendimento, entrevistas com ex-operadores de teleatendimento e acesso a sítios na internet (Orkut) que ofereciam testemunhos e avaliações sobre esse serviço. A leitura de Michel Foucault possibilitou orientar a descrição do controle gerencial presente na arquitetura do local de trabalho e nos mecanismos disciplinares. A noção de trabalho penoso orientou a compreensão das vivências desses trabalhadores que apontavam as repercussões do trabalho para a saúde. Ritmo acelerado, necessidade de ser cordial e rapidez no atendimento são alguns dos motivos de penosidade. Posteriormente, foram tecidas considerações sobre algumas técnicas motivacionais adotadas pelas empresas do setor para lidar com as exigências do trabalho.
\end{abstract}

Palavras-chave: Teleatendimento, Trabalho penoso, Saúde do trabalhador, Psicologia social do trabalho, Psicologia social da saúde, Sociedade disciplinar.

Living in a box: psychosocial dimensions of health and control in the work of telemarketing

The objective of this paper is to study how telemarketing operators experience work in relation to their health. The field study consisted in visiting a telemarketing company, interviewing former telemarketing operators and accessing internet websites (Orkut) that offered testimonials and evaluations on this kind of service. The literature review about Michel Foucault enabled to guide the description of the management control present in workplace architecture and in disciplinary mechanisms. The concept of heavy work oriented the understanding of those workers' experiences, which pointed to the effects of work in health. Accelerated work rhythm, need to be friendly and fast in attendance are some of the reasons for heavy work. Subsequently, considerations were made about some motivational techniques adopted by telemarketing companies to deal with the demands of work.

Keywords: Telemarketing, Laborious work, Worker's health, Social psychology of work, Social psychology of health, Disciplinary society.

\section{Introdução}

E ste artigo descreve uma investigação sobre as vivências de operadores de teleatendimento e sua relação com os contextos de trabalho, tendo como norte o nexo entre trabalho e saúde. A investigação surgiu, inicialmente, como uma proposta de estágio da disciplina Trabalho e saúde: a compreensão a partir da psicologia social, do curso de graduação em psicologia do Instituto de Psicologia da Universidade de São Paulo. O estágio tinha como objetivo conhecer as condições de trabalho de uma determinada categoria de trabalhadores os impactos dessas condições em suas subjetividades e em sua saúde.

\footnotetext{
1 Este artigo foi desenvolvido no âmbito das disciplinas do curso de graduação em psicologia do Instituto de Psicologia da USP "Trabalho e saúde: a compreensão a partir da psicologia social" e "Prática de pesquisa em psicologia social I", ministradas por Leny Sato em 2006. A aluna Débora de Souza Sobral Riciolli também participou de algumas etapas da investigação. Agradecemos a Fábio de Oliveira, que participou de alguns momentos de elaboração da investigação e ofereceu-nos bibliografia.
} 
Para nós, que até então conhecíamos apenas "o lado de cá da linha", como clientes, o serviço de teleatendimento era percebido como algo inconveniente, por invadir nossa privacidade, em nossas casas, por meio de ligações telefônicas e, quando acionávamos esse serviço, por nem sempre conseguíamos ter nossos problemas resolvidos. Assim, adentramos no universo do teleatendimento motivados pela proposta da disciplina e inquietos com um serviço que é muito difundido, porém bastante desconhecido, por nós, do "lado de lá da linha".

Visitamos alguns sítios na internet e descobrimos que em um sítio de relacionamentos, o Orkut, ${ }^{2}$ existiam comunidades nas quais operadores e supervisores de teleatendimento e clientes registravam suas opiniões a respeito desse tipo de serviço. A leitura dos conteúdos dessas manifestações identificou que o serviço ativava emoções fortes e que não havia posições neutras, dado o conteúdo e a forma dos depoimentos, que ora defendiam e ora atacavam a qualidade do serviço, não sem buscar personificar um "culpado" (operadores considerados "incompetentes", supervisores que não eram "realmente" líderes, clientes que não "compreendiam" a lógica do teleatendimento etc.) e, com menos freqüência, esses depoimentos cogitavam que a raiz dos problemas e das insatisfações poderia estar na organização do trabalho. Havia ainda registros sobre o estresse no trabalho e outros problemas de saúde dos trabalhadores. Essa tendência à personificação dos problemas coincide com a compreensão de Linhart (2006) de que o teleatendimento é um caso exemplar das novas formas de relações no mundo do trabalho atual ${ }^{3}$. Como é próprio de sítios desse tipo, o Orkut abre espaço para a polêmica.

Esses indícios nos levaram a buscar mais informações para caracterizar o trabalho no setor. A Associação Brasileira de Telesserviços ${ }^{4}$ (ABT), criada há 19 anos, esperava que em 2006 fossem contratados 675 mil trabalhadores, configurando esse setor como um dos mais importantes geradores de empregos. Em termos comparativos, entre os anos de 1997 e 2001, houve crescimento de postos de trabalho no setor da ordem de $198 \%$, período no qual o $\mathrm{IBGE}^{5}$ registrava retrocesso de $23,3 \%$ dos postos de trabalho na indústria e crescimento de $11 \%$ no setor de serviços (Nogueira, 2006).

A mão de obra é jovem (entre 18 e 25 anos) e muitos experimentam seu primeiro emprego. Cerca de $76,8 \%$ são mulheres, segundo pesquisa da Pontifícia Universidade Católica de São Paulo publicada no sítio da ABT. A jornada de trabalho é de seis horas diárias, cinco ou seis dias por semana. É um trabalho que requer pouca qualificação (oferecida pelo contratante), basta aprender a operar o sistema de informática usado, uma das conseqüências do desenvolvimento da tecnologia da informação combinada com o modelo taylorista (Fernandes, Di Pace \& Passos, 2002) ${ }^{6}$.

O teleatendimento no Brasil teve início no final da década de 70, mas seu crescimento deu-se na década seguinte, quando empresas de diversos segmentos o adotaram como estratégia para se comunicar com os clientes. Com a expansão da informática, o atendimento vem ganhando rapidez e acúmulo de informações, possibilitando um atendimento mais "personalizado", isto é, dirigido ao perfil de consumo de seus clientes.

Teleatendimento pode ser definido como:

\footnotetext{
2 www.orkut.com

3 Para Linhart (2006), o mundo do trabalho atual é menos propício à construção de um projeto coletivo dos trabalhadores, esfumaça a postura crítica, exige um trabalhador mais comprometido com a ideologia organizacional, que trabalhe sempre em busca da melhor "performance".

4 Antes de 2006, Associação Brasileira de Telemarketing.

5 Instituto Brasileiro de Geografia e Estatística.

6 Esses autores também recuperam o debate sobre as conseqüências da tecnologia da informação no sentido inverso: o de requerer maior qualificação técnica dos trabalhadores.
} 
quaisquer atividades por meio de sistemas de informação e múltiplas mídias, com o objetivo de desenvolver ações padronizadas e contínuas de marketing ou favorecer a comunicação com clientes, público ou agências governamentais. Trata-se de usar os sistemas de telefonia, informática e dados (Glina \& Rocha, 2003, p. 11).

Quanto à saúde dos operadores, tínhamos indícios de que suas condições deveriam ser compreendidas à luz de um trabalho repetitivo e monótono, que exigia o contato contínuo com os clientes por meio de ligações telefônicas e que objetivava vender uma infinidade de produtos e de receber reclamações. Esses eram fortes indicadores de que se tratava de um trabalho que suscitava vivências de sofrimento e incômodo e que demandava esforços, ou seja, tratava-se de um trabalho penoso.

As características desse trabalho também nos levaram a Le Guilliant, Roelens, Bégoin, Béquart, Hamsen e Lebreton (1984), que descrevem, em um clássico estudo de 1956, a neurose das telefonistas. Fadiga, insônia, irritabilidade, astenia, problemas gastrointestinais, sentimento de lassidão, sentir-se com os "nervos à flor da pele" e humor depressivo são alguns de seus componentes. A organização do trabalho era desenhada de modo a incentivar a competição entre as trabalhadoras, ter prescritas tarefas repetitivas e monótonas, ter que alcançar metas de produção e ser um trabalho concebido para ser realizado por pessoas sem capacidade de discernimento e responsabilidade.

Dejours (1986) forneceu-nos referência para compreender o que é saúde. Para o autor, baseado em Canguilhem, saúde remete à possibilidade de as pessoas traçarem um caminho original em direção ao bem-estar, o que exige que tenham meios materiais para tanto. $\mathrm{O}$ argumento de Dejours desenvolve-se a partir de uma crítica ao conceito de que saúde é um "estado de bem-estar bio-psico-social e não apenas a ausência de doenças". Sua crítica, que é calcada nas contribuições da fisiologia, da psicossomática e da psicopatologia do trabalho, é a de que o conceito de saúde sustenta-se na noção de variabilidade e não na de estabilidade.

Sato (1993) apresentou-nos elementos para compreender quando um trabalho é penoso (pois suscita sofrimento, incômodo e demanda esforços). Em sua definição de trabalho penoso, o controle do trabalhador sobre o trabalho é central. Não ter controle sobre os contextos de trabalho é o que os torna penosos. Para ter controle, três requisitos são necessários: a familiaridade com o trabalho e seu ambiente social, o poder para interferir nas regras e prescrições de trabalho e o respeito ao limite subjetivo, sempre dinâmico. O controle é objeto de disputa e, como mostrou Marx (1980), os diversos tipos de processos de trabalho na história da sociedade capitalista industrial foram transferindo o controle das mãos dos trabalhadores para as da gerência e do capital, não sem conflito. Ter o controle nas mãos é o que permite participar da definição do que, como, quando e com quem fazer o trabalho.

A arquitetura da sociedade disciplinar que pesa sobre os indivíduos com seus mecanismos e com sua estrutura foi buscada em Foucault (1994).

O objetivo do artigo consistiu em estudar como operadores de teleatendimento vivenciam o trabalho em sua relação com a saúde e norteamo-nos pelas seguintes questões: como o controle gerencial se expressa? O que ele demanda desses trabalhadores? Há possibilidade de os trabalhadores controlarem seus contextos de trabalho? Caso isso não seja possível, como eles vivenciam essa situação, quais as repercussões sentidas e como lidam com tal impossibilidade? 


\section{Aproximação e investigação}

Para responder a essas questões e pensar mais sobre o trabalho em teleatendimento, buscamos diversas formas de aproximação. A primeira, como já foi dito, foi pesquisar no Orkut e na internet em geral como o teleatendimento mostrava-se, tanto a partir dos trabalhadores desse ramo, como dos clientes e usuários desse tipo de serviço. Com esse levantamento em mãos, tínhamos um material muito rico e fomos apresentados à diversidade de termos, funções, críticas e elogios aos serviços de teleatendimento, elementos que suscitaram mais questões sobre essa atividade de trabalho.

Um segundo passo foi a conversa com uma psicóloga que trabalhava em uma grande empresa, que mantém contato com os clientes por meio do teleatendimento. A partir disso pudemos entender melhor o funcionamento desse serviço.

A visita a uma central de teleatendimento foi de extrema importância para propiciar a vivência dos pesquisadores em um ambiente bastante peculiar, para observar os operadores trabalhando e conhecer a estrutura física do ambiente de trabalho, que como será discutido mais adiante, tem um papel muito importante na modelagem e no controle dos trabalhadores em questão.

Após essa etapa, sentíamos falta de conhecer o ponto de vista de trabalhadores e extrabalhadores de teleatendimento, e optamos por realizar entrevistas de modo que os operadores pudessem falar sem script, sem tempo cronometrado, sem headset ${ }^{7}$ e sem monitoramento.

O pedido inicial para os entrevistados foi que falassem da sua experiência como operadores de teleatendimento e as perguntas subseqüentes foram guiadas pelo conteúdo do depoimento do entrevistado.

Apesar de termos adotado esse formato aberto de entrevista, de os entrevistados serem de ambos os sexos, de pertencerem a estratos sociais distintos, de terem nível de escolaridade, idade e se referirem a locais de trabalho distintos, em todas as entrevistas o tema saúde foi trazido espontaneamente, com diferenças na intensidade da emoção que carregavam e nos muitos pontos comuns descritos, possibilitando-nos construir sobre o trabalho de teleatendimento uma visão de trabalho penoso e gerador de sofrimento.

As entrevistas foram concedidas por quatro pessoas, conhecidas dos entrevistadores, porém não próximas. Lúcia, 24 anos, que sempre trabalhou em teleatendimento; na época da entrevista havia pedido demissão para poder estudar. Pâmela, administradora de empresas que trabalhou no início da carreira numa central de atendimento a clientes de um banco. Raquel, 24 anos, estudante universitária, ex-estagiária de uma central de atendimento ao consumidor de uma indústria farmacêutica. Carlos, 30 anos, que trabalhou em teleatendimento por sete anos na mesma empresa, em diferentes funções e hoje é comerciário.

A pesquisa então caminhou no sentido de compreender o que apareceu de comum nas entrevistas, na visita e nas leituras, tendo como embasamento teórico os autores citados na introdução, que foram lembrados e lidos durante a análise dos dados. 


\section{Ponto de partida: distintas possibilidades de vivenciar o trabalho}

Depreendemos que a expectativa em relação ao trabalho no setor de teleatendimento variou de acordo com o projeto de trabalho na vida de cada entrevistado no momento de seu ingresso nessa atividade. Assim, para alguns entrevistados o setor de teleatendimento funcionou como porta de entrada para uma área de trabalho que fazia sentido em sua trajetória profissional naquele momento. No caso de Pâmela, essa era a oportunidade para trabalhar numa grande empresa bancária, desejo da então recém-ingressante em uma faculdade de administração e que anteriormente havia trabalhado em uma loja. Para Raquel, estudante de farmácia, trabalhar no setor de telemarketing de uma importante indústria farmacêutica era a oportunidade para realizar estágio em sua área de especialização. Em ambos os casos, trabalhar em teleatendimento fez parte de uma estratégia em termos de construção de uma carreira profissional numa empresa ou em uma profissão: o sentido desse trabalho na trajetória profissional é o de meio e não de fim.

Para outros dois entrevistados, a entrada no setor foi a possibilidade de garantir emprego, não tendo configurado-se por uma intenção estratégica desenhada por eles. No caso de Lúcia, trata-se de uma ex-telefonista que "acabou entrando" no setor de teleatendimento. No outro, o de Carlos, trata-se do segundo emprego de um ex-office-boy.

Em todos os casos, entretanto, trabalhar no setor de teleatendimento não foi fruto de uma escolha, mas esses trabalhadores foram absorvidos pela oferta de emprego no mercado formal de trabalho, tendo em vista o grande número de vagas oferecidas pelo setor.

Expectativas diferentes mobilizaram modos diferentes de interpretar a experiência de trabalho no teleatendimento. Isso pôde ser observado tanto nos temas espontaneamente verbalizados, como na carga emocional emprestada aos depoimentos. Nas falas daqueles em que esse trabalho fazia algum sentido na trajetória profissional, o modo de lidar com as várias situações do contexto e com a rotina pesada e estressante (entre outros problemas) aparecia de uma maneira mais branda. Tonalidade próxima é também observada para aquele em que o trabalho no teleatendimento faz parte do passado e que agora trabalha em outro ramo (comércio). Para Lúcia, que por hora não vislumbra outra atividade de trabalho, a crítica ao teleatendimento apareceu de modo mais contundente e explícito, aproximando-se de um tom de revolta. Esses fatos levam a concluir que o sentido do trabalho na vida dos entrevistados permitiu que encarassem diferentemente a experiência, matizando o tom de suas vivências.

Certo é que todos, independentemente do tom dado à vivência no teleatendimento, relataram uma rotina pesada e estressante e que nunca sonharam em "ficar no mundo do telemarketing, pelo amor de Deus!".

\section{Construindo o contexto de trabalho}

Através das entrevistas, da visita e dos depoimentos no site de relacionamentos Orkut, observamos o quão diverso é o campo de trabalho do teleatendimento, embora também tenha sido possível apreender uma lógica comum a eles.

Através de uma simples frase, Raquel define o papel que o teleatendimento desempenha nas empresas: "a gente é porta de entrada". Apesar de ela restringir a definição à área em que trabalha, um serviço de atendimento ao consumidor/cliente (SAC), é possível conceber que o papel do teleatendimento em geral é esse mesmo definido por Raquel. Isso porque o teleatendimento estabelece a comunicação direta da empresa com o cliente. Assim, 
a pessoa do operador é o canal pelo qual se dá essa comunicação. Para o cliente, ele é a voz da empresa; é o operador, através dos recursos que tem, que encarna o discurso que a instituição quer transmitir.

Da perspectiva do jovem operador, ele se configura em um porta-voz da empresa, forjado pela organização disciplinar. Que tipo de exigências a instituição faz ao operador para que seja um bom porta-voz? Como é a formação desse porta-voz e quais são os tipos de mecanismos de fiscalização para que esse porta-voz da empresa, "nunca se cale" e transmita a mensagem requerida e da maneira correta?

\section{A arquitetura do espaço}

Na visita aos diferentes setores de teleatendimento de uma grande empresa, uma primeira característica saltava aos olhos: a forma como o espaço era organizado. Os salões onde se encontravam os trabalhadores era esquadrinhados por um grande número de divisórias. Os operadores eram agrupados em células onde eram separados por divisórias individuais, as baias, conforme ilustrado pela figura abaixo.

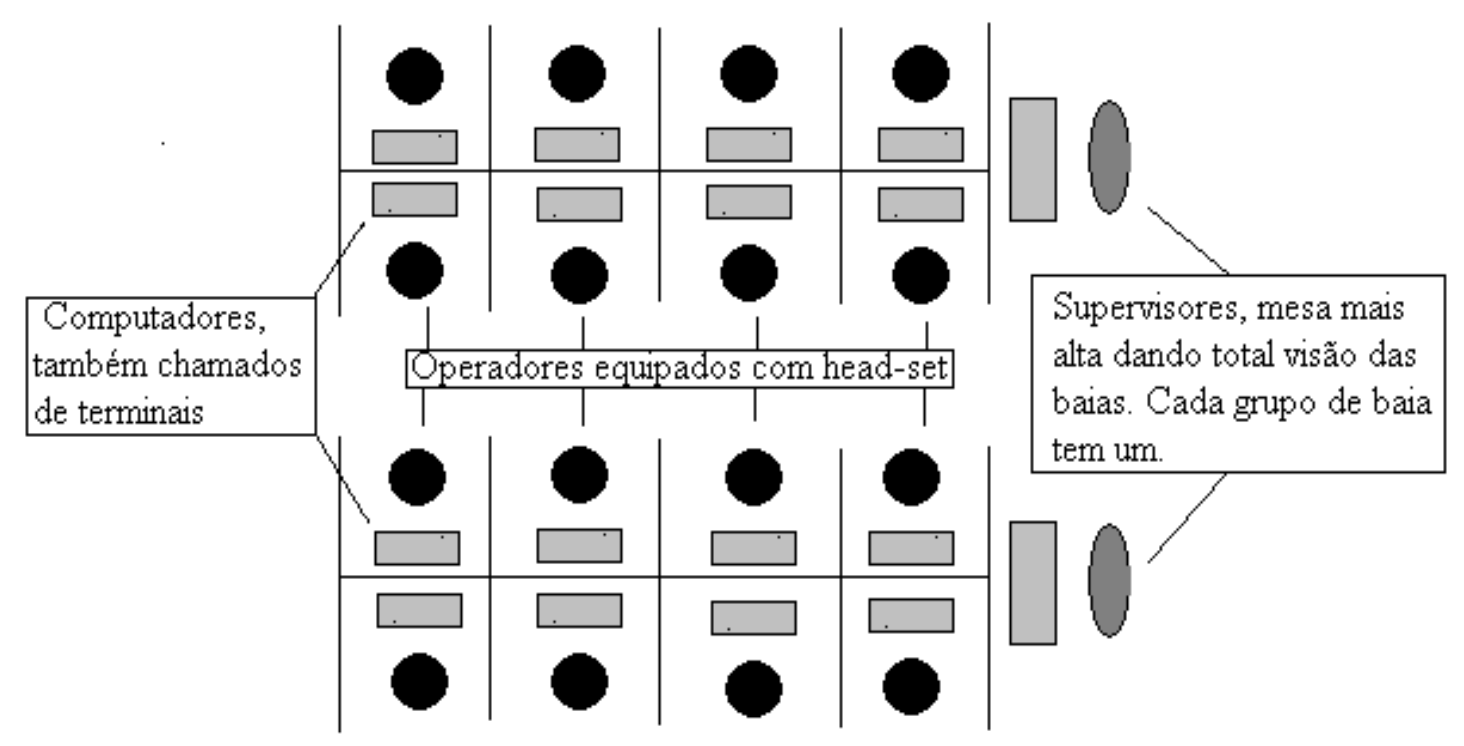

Cada célula é composta por um número fixo de operadores e por um supervisor. $\mathrm{O}$ número de trabalhadores por célula depende da empresa e do setor de serviço de atendimento. No entanto, algo comum, relatado pelos entrevistados, era o fato de os operadores não poderem mudar de célula. Carlos explica o motivo:

Então, na frente de cada célula tinha uma mesa da supervisão, então, por conseqüência você é obrigado a sentar só naquela célula, o computador, a baia, você escolhe, mas basicamente você ficava sempre no mesmo lugar. Só quando a supervisão mudava ou você mudava de supervisão, mas basicamente era o mesmo lugar.

Portanto cada célula tem o seu supervisor que tem sob seus cuidados sempre os mesmos atendentes.

A baia é composta por um computador, uma cadeira, um headset (que dependendo da empresa ficava em posse do trabalhador) e, eventualmente, um bloco de notas. Uma das 
entrevistadas descreve como se sentia dentro da baia: "é muito preso. É uma tela, um headset e um fone. Só. Você não vê nada diferente, é só aquilo e acabou" (Pâmela). Outro entrevistado também fala de sua impressão em relação à baia: "...ela é bem individual mesmo, tem empresa que você não consegue nem olhar para o colega do lado, de tão estreita e tão fechada que ela é. Aí você fica ali, é você, o computador e só" (Carlos). Assim, o atendente fica limitado e isolado em uma pequena área, sem possibilidades de contato com os colegas do lado e da frente; as divisórias da baia limitam a movimentação e no seu campo de visão encontra-se apenas o computador ao qual ele está ligado pelo headset.

O espaço é esquadrinhado respeitando a lógica de: "cada indivíduo no seu lugar; e em cada lugar um indivíduo" (Foucault, 1994, p. 131). O trabalhador torna-se localizável, visível aos agentes de vigilância que têm como "saber onde e quando encontrar os indivíduos, instaurar as comunicações úteis, interromper as outras, poder a cada instante vigiar o comportamento de cada um, apreciá-lo, sancioná-lo, medir as qualidades ou os méritos" (Foucault, 1994, p. 131).

A baia, portanto, é um espaço com o propósito de manter o operador concentrado, constantemente, no trabalho. Com todos os principais sentidos ocupados pela tela do computador, pelo headset e pelo teclado, o operador, assim como disse uma das entrevistadas, fica "preso", enjaulado. Ao longo do tempo o corpo disciplina-se e realiza suas tarefas quase que de forma automática.

Portanto, a estruturação do espaço físico permite apenas um tipo de comunicação, a com o cliente - e essa comunicação também tem suas restrições. Com isso, a manutenção do papel de porta-voz da empresa já é garantida pela conformação do espaço físico.

\section{O script e a supressão do sujeito}

Os entrevistados mostraram as exigências que lhes são feitas pela empresa para que ocupem de forma satisfatória a posição de porta-voz. Para sintetizar parte dessas exigências, valemo-nos da fala de Pâmela: "... você tinha que ser educado, cordial, do jeito que eles queriam, mas você tinha que ser pontual...". Para que essas demandas da empresa sejam atendidas "tinha que seguir basicamente o script e tinha todas aquelas normas de tratamento, de postura, do lado de cá do telefone" (Carlos). Aqui aparece um outro instrumento disciplinar: o script.

O script é um texto-base, fornecido pela empresa, que o operador toma como guia para orientá-lo em todos os atendimentos. O script pode ser usado no decorrer dos atendimentos como um texto a ser lido pelo operador, nesse caso, o script é utilizado de forma explícita. Há também outra modalidade, denominada de "script livre", na qual o operador não precisaria repetir ao cliente os dizeres de um texto-padrão, mas segue determinados pontos pré-estabelecidos dentro de algumas regras de comportamento impostas pela empresa.

O emprego de script também depende do tipo de serviço que o setor presta. Por exemplo, nos setores que demandam dos operadores atuação no sentido de persuadir os clientes, não se utiliza compulsoriamente o script. Esse é o caso quando se pretende convencer o cliente a não cancelar a compra de um serviço, visando reter a clientela (setor de retenção), ou quando se busca ampliar a clientela da empresa, como é o caso do setor de vendas ativo. Em serviços de atendimento ao consumidor (os SACs) pode-se utilizar compulsoriamente o script. Apesar das variações, o script "é mais para padronizar a resposta de todo mundo [operadores]" (Raquel).

No caso do script livre, é possível supor que não há um controle disciplinar (que esquadrinharia cada movimento, cada palavra, cada tipo de resposta), mas sim um controle 
que visa a modulação. Molda-se o comportamento dos operadores dentro de determinados limites, como se tomássemos os comportamentos esperados dentro de uma curva normal, em que os desvios são aceitos dentro de certos limites, um desvio padrão. $O$ controle sobre a fala do operador sempre existe, quer seja o script explícito ou não. No caso do script livre o controle é internalizado. O discurso, além de ser reproduzido de forma repetitiva pelo operador - o que permite que seja transmitido de forma automática -, é-lhe constantemente apresentado e atualizado por meio de treinamentos e palestras. Com isso, o controle sobre o trabalhador por meio do script é internalizado, parecendo não lhe ter sido imposto. $\mathrm{O}$ controle sobre a fala do operador dá-se pelo conteúdo (o quê se fala) e pela forma (como se fala).

Porém, a exigência não pára aí. O operador, como relata um dos entrevistados, tem que "ler o script sem parecer que está lendo". Além disso, ele "tem que mostrar naturalidade e falar de uma forma padronizada, mas não um robô". Essa tarefa que parece paradoxal é uma das essências do trabalho do teleatendimento. $O$ trabalhador vê-se frente ao trabalho de transformar o padronizado em singular. No entanto, nessa tarefa a singularidade do operador - e, parece-nos, a do cliente também - é esquadrinhada e disciplinada pela tarefa maçante de reprodução de um texto, de um discurso imposto pela empresa. Essa tarefa paradoxal não se restringe ao conteúdo do discurso, mas ao comportamento que os operadores devem exibir ao se relacionarem com os clientes.

O operador deve ser cordial. A cordialidade não se desenvolve de forma natural, mas é imposta pela empresa. Nesse contexto, o afeto do operador é moldado dentro de um padrão que torna o discurso e a forma de se expressar instrumentos de trabalho. Essa obrigação é cumprida, mas não sem sacrifícios. Independentemente do estado físico e emocional do operador, durante a ligação telefônica ele deve se comportar orientado pelo padrão de regras pré-estabelecido pela empresa com vistas a ser cordial e educado com o cliente. O operador pode estar "com taquicardia, estar tremendo, e nem é tremendo de frio, é tremendo de raiva" (Raquel), mas a regra tem que ser mantida, sob pena de sofrer punições. Do outro lado da linha, o cliente, ao menos teoricamente, tem a liberdade de se expressar conforme seus sentimentos e age sem seguir padrões. Com isso, o operador situa-se entre dois pólos distintos que determinam sua forma de agir: de um lado, vê-se pressionado a seguir os padrões prescritos e, de outro, deve responder à diversidade das interpelações dos clientes. $\mathrm{O}$ operador, com seu "jogo de cintura" e com sua "maleabilidade", deve contornar a situação e transformar o padronizado em singular. Deve transformar a presença da regra em algo imperceptível aos olhos do cliente; deve transformar o robô em ser humano, negando a sua própria humanidade, pois ao fazê-lo ele submete seus sentimentos à padronização fria e funcional.

O script e as regras de comportamento visam, então, garantir que a mensagem transmitida pelo operador seja aquela que a empresa quer transmitir. São técnicas adotadas com vistas a tornar a relação com o cliente o mais eficiente possível. O script e as regras visam garantir, o máximo possível, que a conversa seja funcional, que seja mais eficiente e eficaz, contemplando, dessa maneira, tanto a demanda do cliente quanto a da empresa. Um outro aspecto também influi no atendimento: o tempo.

\section{O tempo do capital}

Segundo a lógica da empresa, ela deve estar sempre disponível para atender a demanda do cliente, portanto, seu porta-voz (o setor de teleatendimento) deve garantir que os operadores estejam sempre de prontidão para entrar em ação sempre que houver um 
cliente a ser atendido. Dessa forma configura-se outra exigência, além da cordialidade e da pontualidade: o estado de prontidão.

Determinado o turno de trabalho o operador "chega no seu horário, 'loga' no sistema e a partir dai recebe a primeira ligação. E vai atendendo" (Carlos). Enquanto o atendente permanece "logado" (conectado ao sistema) ele está apto a receber as ligações. Durante uma jornada de trabalho de seis horas e com o direito a quinze minutos de almoço, "as ligações vão chegando... É automática, a maioria dos sistemas de empresas grandes é automático". Ao desligar o telefone, o sistema automaticamente encaminha outra ligação para ser atendida e o tempo "de uma ligação para outra eram dois segundos de diferença" (Pâmela). O controle do intervalo das ligações não é feito pelo operador, mas sim por um sistema. Esse intervalo, imposto de forma objetiva e padronizada, não respeita o tempo subjetivo do operador para preparar-se para o próximo atendimento. Como conseqüência, o operador, talvez como uma forma de manter um mínimo de controle sobre o seu trabalho, altera sua percepção de um tempo "que aparentemente não é perceptivel" (Pâmela), mas que com o tempo e a necessidade ele "sente a diferença de dois segundos" (Pâmela).

Assim como em uma linha de montagem, o ritmo das ligações não é cadenciado pelo trabalhador. Ele tem que se adaptar da melhor forma possível ao ritmo que lhe é imposto. Um parâmetro da empresa para aumentar o ritmo dos operadores é a fila de espera (clientes em espera para serem atendidos), que foi qualificada por um entrevistado como "tenebrosa". Quando a fila se forma, a pressão por parte da empresa aumenta e o operador vê-se em uma encruzilhada, devendo responder a demandas opostas em um só ato: respeitar a singularidade do cliente, manter a cordialidade e submeter-se à objetividade do ritmo de produção.

O operador vive constantemente essa exigência paradoxal, pois a avaliação de seu desempenho leva em conta tanto a qualidade do atendimento, como o tempo despendido sempre registrado e controlado. Em geral existe o tempo de ligação médio (TMA) e, no final do dia, a média de tempo de atendimento de cada trabalhador deve se aproximar do TMA, que varia de empresa para empresa. As empresas estipulam metas de atendimentos, por exemplo, na empresa em que um dos entrevistados trabalhou a média de atendimentos diários era entre oitenta e cem ligações.

O período em que o operador não se encontra "logado" é rigorosamente cronometrado. Pâmela descreve assim essa situação: "cada pausa que eu ia fazer eu tinha que digitar o que eu ia fazer, então eu tinha quinze minutos de almoço, tinha que ser rigorosamente quinze minutos e tinha dez minutos de banheiro, que também era rigoroso". Esse controle rigoroso do tempo apareceu com muita ênfase nas entrevistas e, no caso de algum imprevisto obrigar o operador a ultrapassar o tempo de intervalo estipulado, ele deveria submeter-se a procedimentos de controle: "Se eu tivesse algum problema poderia justificar, tinha que justificar porque você estava fazendo mais que dez minutos, dai eu tinha uma planilhinha e justificava manualmente" (Pâmela).

O controle sobre o trabalhador faz-se a partir de uma arquitetura que combina controle do tempo e do ritmo de trabalho, a estrutura espacial (organização e distribuição das pessoas no local de trabalho) e o posto de trabalho em si, que mantém o operador sempre conectado, sempre de prontidão, sempre na posição de porta-voz. Dessa forma as relações interpessoais no trabalho ficam prejudicadas, sendo que o operador "não tem amizade mesmo com quase ninguém" (Carlos), "não tem muita intimidade" (Lúcia), apesar de que "normalmente os operadores são bem unidos, basicamente estão passando pelas mesmas coisas, mas ai tem que ver se há ou não a possibilidade de se conversar sobre o que se passa. Normalmente não tem tempo" (Lúcia). Com isso, a única possibilidade de se relacionar com colegas é "de repente, num intervalo entre uma coisa e outra, você troca uma idéinha" (Lúcia).

Assim, o tempo considerado não produtivo torna-se um fator que deve ser controlado e medido a qualquer custo pela empresa, pois, como uma empresa de uma sociedade 
capitalista, "todo o tempo deve ser consumido, negociado, utilizado; é uma ofensa que a força de trabalho meramente passe o tempo" (Thompson, 1998, p. 298). Nesse sentido, todo o tempo deve ser voltado para a produção, portanto, qualquer comportamento que não seja produtivo deve ser justificado, caso contrário é punido e banido. Assim o "tempo do assalariado pertence ao empregador, que o comprou e pode usá-lo da maneira mais rentável segundo seu ponto de vista" (Linhart, 2006).

\section{O treinamento: adquirindo comportamentos}

O futuro operador de teleatendimento deve aprender essa rotina, os comportamentos cordiais, pontuais e sempre a tempo para ser o porta-voz da empresa. Para tanto, o treinamento (que pode ser feito em serviço) é o período em que o operador é introduzido à lógica dessa rotina. Na experiência dos entrevistados, esse período variou de dez dias a três meses. Também relatam formas variadas de tomar contato com o trabalho de operador de teleatendimento. Os treinamentos podem ser teóricos (como, por exemplo, estudar procedimentos, familiarizar-se com as siglas empregadas) e práticos (como fazer simulações). Comum a todos é a primeira experiência de acompanhar, como ouvinte, o atendimento de um operador mais experiente. Os primeiros atendimentos podem ser feitos com o auxílio de um colega.

Segundo uma das entrevistadas, o período ideal de treinamento seria de três meses, tempo em que aprenderia como um "carrapato" (ou "carona"), fazendo simulações, tomando contato com os procedimentos, ou seja, seria um espaço de preparação. No entanto, apenas um dos entrevistados obteve um treinamento dentro desse tempo ideal e valendo-se desses recursos. Na realidade, eles relatam que foram obrigados a atender antes de terminar o período de treinamento devido ao excesso de clientes. Uma das entrevistadas relata como foi essa experiência: “...o primeiro atendimento foi 'power' porque estava precisando de gente e como tava precisando eu tinha que aprender tudo muito rápido... O primeiro atendimento é péssimo, por que você treme, não sabe o que responder, onde que estão as respostas e sempre no primeiro atendimento sempre fica uma pessoa que já tem experiência para te auxiliar, mas é assim: você fica tremendo, não sabe o que responder" (Raquel). Por meio desse relato é possível perceber a importância de um período de preparação, pois, em caso contrário, "aí fica mais difícil. É mais maçante... dá sono, você fica cheio de dúvidas..." (Lúcia). Mas esse tipo de situação não é uniforme, "dependendo da empresa você tem mais informação, dependendo da empresa você não tem informação nenhuma, você aprende escutando" (Lúcia).

Há diferenças em termos de capacitação. Há atividades em que informações técnicas especializadas são necessárias, como, por exemplo, fazer operações bancárias ou dirimir dúvidas com relação a medicamentos.

Apesar de tudo, Carlos - que obteve treinamento, a princípio, mais próximo ao ideal (por um período adequado e com os recursos devidos) - define-o como uma "lavagem cerebral" na qual se deve que decorar um número muito grande de siglas e de procedimentos. Assim, os treinamentos não têm como propósito propiciar formação e desenvolvimento profissional. A experiência dos entrevistados coincide com o que Vilela e Assunção (2004) identificaram em pesquisa com empresas de teleatendimento no estado de Minas Gerais. Os autores apontam que os prazos de treinamento e qualificação são demasiado curtos e, por isso, somado a outros fatores, levam a um aprendizado voltado para garantir eficiência e produtividade apenas.

Já no período de treinamento, o operador experiencia a vigilância sistemática sobre si mesmo, que não cessa. Essa vigilância - que ocorre por meio do trabalho de "monitoria" - tem 
por finalidade promover o contínuo ajustamento. "Tudo é sempre revisto, tudo é sempre escutado, tudo é sempre analisado" (Lúcia).

\section{A hierarquia}

Em termos hierárquicos, o supervisor é o superior imediato dos operadores. Sua função é a de fiscalizar o trabalho do operador. Como um vigilante no alto da sua torre ele observa cada passo de seus supervisionados:

Cada célula tinha um supervisor, então qualquer problema que eu tinha durante o atendimento eu me reportava à supervisão e ela ficava controlando as ligações, o tempo de atendimento (...), ele ficava na ponta da célula, num lugar mais alto e tinha a visão de todos os atendentes (Pâmela).

Essa descrição remete-nos à imagem do supervisor de fábrica no início da era industrial. Os entrevistados também reconhecem no supervisor o papel de salva-guarda, de alguém que pode ajudar os operadores.

Além da observação direta, o supervisor vale-se de outro recurso que aparece como constante em todas as entrevistas, que é a monitoria. Ela consiste na escuta de um ou mais atendimentos dos operadores, pelos supervisores. Os entrevistados relatam que, com bastante freqüência, principalmente quando o intuito da monitoria é o de avaliar o desempenho do operador, ela é realizada sem o conhecimento da pessoa que está sendo avaliada. "Eles fazem a monitoração ali ao vivo, você não sabe que eles estão te monitorando" (Carlos). Esse monitoramento não é realizado periodicamente, mas em intervalos mais esparsos - de quinze em quinze dias ou de mês em mês, variando de empresa para empresa. No entanto, o supervisor tem a possibilidade de a qualquer momento escutar as ligações feitas pelos operadores. Isso normalmente acontece "quando o supervisor via que [algum operador] estava há muito tempo em uma ligação" (Carlos) ou quando percebia que algum problema estava acontecendo. Além desse tipo de avaliação há um outro: "logo que a ligação [de um atendimento termina]... ele liga para você, como um cliente, e você tem que ter toda a postura, padrão, aí ele te passa alguma informação, para te dar uma resposta, um feedback” (Lúcia). Essa monitoria também pode ser feita em outro momento, fora dos atendimentos, através da gravação das ligações e é realizada, dependendo da empresa, por um gerente ou pelo próprio supervisor.

Assim, a monitoria poderia ser equiparável ao exame descrito por Foucault (1994), pois

combina as técnicas da hierarquia que vigia e as da sanção que normaliza. É um controle normalizante, uma vigilância que permite qualificar, classificar e punir. Estabelece sobre os indivíduos uma visibilidade através da qual eles são diferenciados, sancionados". (Foucault, 1994, p. 164).

Além disso, também se compara ao exame, quando "inverte a economia da visibilidade no exercício do poder". De forma silenciosa a monitoria avalia o trabalho do operador que não sabe que está sendo monitorado. Justamente o não saber mantém o operador em estado de alerta e preocupado em manter os padrões de qualidade e de produtividade impostos pela empresa, já que tem consciência de que pode ser vigiado a qualquer momento. 
Com isso, a monitoria torna-se um agente disciplinador poderoso, pois, ao colocar em evidência o atendente, faz com que ele mantenha a produção e "sem isso o supervisor não consegue saber quem produz e quem não produz" (Carlos).

A partir dos dados coletados pela monitoria e daqueles de outras fontes é feita a avaliação de desempenho do operador e com base nela é dado um feedback. Essa avaliação pode ser através de "grandes reuniões com todo mundo, onde eles falam de todo mundo" ou pode ser de forma pessoal sendo que "cada um tem a sua avaliação pessoal de estágio, então... você conversa com o seu chefe... e é a partir dai que você tem uma idéia de como você trabalha" (Raquel). Essa conversa consiste em uma análise de como estão sendo feitos os atendimentos, quando se apontam os erros e os pontos positivos.

O feedback pode ser uma conversa onde "te passavam uma espécie de gráfico de como você atendia, de como você era educado, como você falava no telefone, dava um feedback completo de como você de comportava do lado de cá da linha" (Carlos). Assim, é a partir dessa avaliação que pode surgir a oportunidade para o recebimento de bonificações nos salários, de prêmios ou de punições que podem ser desde advertências verbais, até descontos nos adicionais de salário.

Com isso, esses recursos de avaliações e gratificações tornam-se um meio eficiente de a empresa ter o conhecimento sobre o operador e ao mesmo tempo padronizar os procedimentos, apontando de maneira objetiva, através de planilhas e gráficos, os pontos fortes e fracos de cada pessoa em termos de produtividade e eficiência. Com isso, a empresa, aos poucos, faz com que o operador reconheça aqueles comportamentos considerados não produtivos como algo a ser descartado. No entanto, esses comportamentos podem ser formas de resistência a um trabalho que pode vir a ser prejudicial à saúde.

São diversos mecanismos e instrumentos que visam disciplinar o comportamento do operador: a monitoria, a atuação do supervisor, o recurso a dados sistematizados em gráficos e tabelas, as metas estipuladas, a política de recursos humanos, as avaliações de desempenho em grupo e individual, o feedback, as punições salariais e verbais, a baia, a rotatividade, além do treinamento.

\section{A vivência e suas repercussões na saúde do trabalhador}

Diante dessa dimensão de controle, pudemos constatar que esse trabalho gera sofrimento; é um trabalho penoso. As entrevistas deixaram isso claro quando o tema é tratado sem que seja sugerido ou perguntado. Definir o trabalho no teleatendimento é fazê-lo incluindo essa dimensão do sofrimento e da penosidade. Termos como, "guerra de nervos", "loucura", "agüentar", trabalho que "pira", "estresse total", "serviço pauleira", dentre outros, são reveladores da vivência desses trabalhadores.

Trabalho penoso "diz respeito aos contextos de trabalho geradores de incômodo, esforço e sofrimento físico e mental, sentido como demasiados, sobre os quais o trabalhador não tem controle" (Sato, 1993, p. 197). Ligações sem intervalo, script, monitoria, má posição corporal durante o trabalho, impossibilidade de ir ao banheiro, dificuldade de construir uma carreira profissional, impossibilidade de interferir nas condições de trabalho, rotina, arquitetura, a lógica disciplinar, entre outros, são aspectos que configuram um contexto de trabalho que se relaciona com o sofrimento desses trabalhadores e, conseqüentemente, com a atribuição de penosidade a esse trabalho. Além disso, o controle gerencial, tal qual descrito acima, deixa pouco espaço para que os trabalhadores controlem o contexto de trabalho de 
modo a respeitar seus limites subjetivos, pois o poder da função de operador de teleatendimento é praticamente nulo. Assim, Lúcia expressa sua vivência nesse contexto:

você respira muito, você fala mal, você senta numa cadeira onde você fica o tempo todo em cima do seu estômago, você não tem tempo de comer, estressa, tal... tem tendinite, problema na coluna... isso eu descobri esse ano, tenho umas vértebras fora do lugar, cadeira, posição, postura... eles não estão muito importados com isso, não estão preocupados com isso... e por último, eu nunca tinha tido dor de ouvido e esse ano que passou eu peguei uma infecção, porque nessa empresa eles não tinham um protetor auricular 8 que tem que ter e eles não tinham (Lúcia).

A fala de Lúcia expressa o fato de os sofrimentos físico e mental estarem simultaneamente presentes, tanto devido a condições materiais (arquitetura, equipamentos etc.), como à organização do trabalho (conteúdo da tarefa, ritmo, relações interpessoais no trabalho etc.).

Ainda que na perspectiva dos entrevistados seja o contexto geral de trabalho que se relaciona com os problemas de saúde, é a dimensão do controle gerencial sobre o tempo e sobre o comportamento que se destaca em suas falas. Há um tempo que não é um "tempo de si", o limite subjetivo (Sato, 1991), mas o da produtividade, do atender o maior número de ligações possíveis, de ser cordial, pontual e estar sempre de prontidão. O "tempo de si" fica restrito a:

Quinze minutos. Quinze minutos [de intervalo]. Durante esses quinze minutos eu podia comer, ir ao banheiro... e só. Se fosse antes, você tinha que parar e pedir permissão, antes desse quinze minutos. Se fosse depois, provavelmente seria descontado... provavelmente não; era descontado do seu salário (Lúcia).

Diante desse controle gerencial sobre o tempo, a percepção dos ínfimos intervalos entre ligações torna-se aguçada: "o tempo lá é muito cronometrado, você sente a diferença de dois segundos, né? Que aparentemente não é perceptível, mas lá era (...) quando ele [cliente] desliga, eu desligava também e já entrava outra ligação, dois segundos já entrava outra tela" (Pâmela). E parece ser o aguçamento da percepção o que permite um grau mínimo de previsibilidade e de preparação para atender aos clientes.

Um aspecto que se destaca nesse ritmo é o estresse, mantido no trabalho pelo fato de os operadores não terem controle sobre o trabalho, ou seja, de estarem impossibilitados de realizar qualquer tipo de mudança. Assim, o controle gerencial sobre o tempo e sobre o comportamento, reforça o sentimento de "loucura", de "estresse total" vivido no trabalho, uma vez que "você está o tempo todo correndo atrás de uma merda que você sabe que nunca vai chegar, você nunca vai chegar naquela perfeição [metas estabelecidas pela gerência]".

Como as telefonistas de Le Guillant et al. (1984), "não tomar nenhuma iniciativa, não poder organizar elas mesmas o seu trabalho, não acrescentar nada delas mesmas ao trabalho" (p. 10), leva ao cansaço, ao desgaste físico e psíquico e à sensação de inutilidade.

O fato de não poderem exercer nenhuma mudança no trabalho, leva os operadores a estabelecerem uma relação paradoxal com o cliente, geradora de estresse e sofrimento: de um lado, o cliente espera ter suas necessidades atendidas e, teoricamente, a função do atendente seria essa, mas este vê-se impossibilitado de atender o primeiro justamente por seguir as prescrições da empresa. Assim, além do sentimento de não cumprir com sua função diante do cliente, o atendente ouve, com razão, reclamações do cliente, que não é atendido em suas necessidades. "Tem consumidor que não entende (...), não entende e te trata mal, como se você 
tivesse passando uma informação e a culpa fosse sua e isso tá acontecendo porque a culpa é sua..." (Raquel).

\section{Operador: um número de prontidão}

A arquitetura disciplinar constrói o contexto no qual os entrevistados sentem-se como "robôs" que devem demonstrar "naturalidade", mesmo estando em um ambiente extremamente controlado e artificial.

As relações interpessoais são coisificadas, os operadores passam a ser "um número, você não é uma pessoa... e como tem essa troca muito forte de pessoas, eles [gerência] falam para você que você é só mais um, então... não tem problema..." (Lúcia). Uma das entrevistadas informa que o nome fictício, inclusive, é atribuído pela empresa: "eu tinha um codinome, no começo era Ana Daiane (...) eles escolheram. A princípio, era Alícia, eu que escolhi, mas depois, como cresceu muito, aí eles escolheram" (Pâmela).

Nesse sentido, tudo que é humano não deve aparecer no trabalho. Mais que isso, é proibido. As necessidades mais básicas são experimentadas como desajustes, e daí a sensação de desumanização. Dessa forma, ter necessidade de ir ao banheiro, de tomar água, de conversar com os colegas ou fazer amigos é bastante difícil em um ambiente em que são alocadas centenas de pessoas. Falar livremente com os clientes, sem regras e tempos rígidos, ouvindo-os em suas necessidades (mesmo que com a clara intenção de resolver seus problemas) é vivido como motivo claro de punição. Tudo isso é sentido como algo que prejudica a produtividade e que é impossível pela rotina diária - quando, em média, cada operador faz cento e quarenta ligações num período de seis horas ${ }^{10}$.

Dessa forma, o estabelecimento de laços sociais não se firma e, muito menos, a constituição de um coletivo de trabalhadores de modo a identificar interesses, necessidades e vivências semelhantes.

Por isso, seguir um script, ter um nome fictício, ser o porta-voz da empresa e estar numa baia faz parte do contexto de "robôs", que devem demonstrar "naturalidade", mesmo estando num ambiente de condições tão artificiais.

Isso é vivido como sofrimento pelos operadores diante da "desorganização" da empresa. Porém, quando há a possibilidade de relacionarem-se, vemos que o tom da entrevista muda e sentem a necessidade de resgatar a humanidade perdida, pois eles podem usar sua voz, sentir seu tempo, suas necessidades, fazendo críticas e modificações no trabalho.

Raquel revela que esse tipo de relação fortalece o grupo de operadores no sentido de auxiliarem-se mutuamente na realização das tarefas de trabalho, constituindo-se assim, uma equipe, que compartilha informações, experiências e, sobretudo, lidam com os imprevistos e com o desconhecimento no trabalho. Raquel demonstra que se sentem fortalecidos individualmente quando se sentem participantes de um coletivo e podem, inclusive, reivindicar mudanças, como relatou Lúcia: "a gente negociava". Assim, sentiam menos o peso do trabalho e do isolamento.

Mas, mesmo diante dessa possibilidade de imprimir um caráter mais humano ao trabalho, de os operadores se sentirem mais "donos" do que fazem, com o tempo, "parece que vai dando uma coisa, você olha aquela tela, a ligação, você começa a se sentir mal assim, não sei explicar, mas é uma sensação ruim, porque é muito preso" (Pâmela).

9 Aqui a entrevistada refere-se à alta rotatividade de trabalhadores.

10 Média para um grande SAC, citação de uma entrevistada. 


\section{O cerco: vivendo na baia}

Mesmo que o tom dos depoimentos dos entrevistados seja bastante matizado no que se refere a sofrimento, esforço e incômodo no trabalho, todos mostram que a baia que isola cada posto de trabalho tem repercussões para a vivência de estar-se em um cerco.

Sentir-se preso, como relatou a entrevistada Pâmela, é uma vivência compatível com o fato de os operadores verem seu espaço de atuação restrito aos limites da baia. Fisicamente arquitetada, a baia não restringe suas repercussões ao corpo, mas as prolonga para a experiência psicológica, o que intensifica o sofrimento vivido.

Os operadores vêem-se cercados pelas impossibilidades de mudança e de serem eles mesmos; de imprimirem um tom personalizado ao trabalho; de controlarem e modificarem seu trabalho.

Os entrevistados sentem-se cercados pela dificuldade, quase impossibilidade, de mudar de função dentro do setor. Quando a gerência acena com essa possibilidade, as exigências aumentam: fazer horas extras, "bater metas", ajudar em treinamentos etc. Porém, sabem os operadores que não há lugar para todos no nível superior da hierarquia, pois, em geral, são centenas de atendentes e apenas poucos supervisores e um gerente ${ }^{11}$. Um dos entrevistados mostra claramente que percebe tratar-se de uma estratégia de sedução da empresa.

\section{Com os "cinco sentidos ligados" e entrando em curto-circuito}

Para de uma situação "momentânea" de estresse passar ao sofrimento, psíquico e físico permanente, não é preciso muito. Tudo que descrevemos acima facilita e desencadeia o surgimento de sofrimento e incômodo.

Tendinite, estresse, problemas na coluna, inflamação no ouvido, problemas gástricos, infecção urinária, problemas respiratórios, rouquidão, depressão, hipertensão são algumas das patologias ou sintomas referidos pelos entrevistados como decorrentes do trabalho. Problemas de saúde reveladores da amplitude do envolvimento físico e mental exigido dos operadores no trabalho. Afinal, eles ficam

o dia inteiro com os cinco sentidos ligados, o negócio no seu ouvido o tempo todo, sua visão o tempo todo, tá usando no telefone, no computador, as mãos o tempo todo trabalhando, você está digitando números de telefone ou teclando (...) pô, não tem como não ficar estressado. Ou é estresse ou depressão! (Lúcia).

O termo "estresse" é empregado pelos entrevistados para identificar o sofrimento ligado à pressão da rotina, da gerência e das metas e à impossibilidade de responder às necessidades dos clientes, enquanto o termo "depressão" é empregado para qualificar a vivência relativa à falta de perspectiva, à impossibilidade de mudança no trabalho, de função e mesmo de atividade.

Um dos entrevistados refere ter sido afastado do trabalho por motivo de saúde: "Eu tive crise de estresse, fiquei alguns meses... eu tive hipertensão, comecei a tomar remédio. Fiquei afastado, poucos dias, mas fiquei, uns 15 dias mais ou menos. E eu decidi parar, eu não agüentava mais!" (Carlos).

11 Em média, cada supervisor é responsável por cerca de vinte operadores e um gerente é responsável por quatro células. 
O estresse aparece não apenas durante o trabalho, mas também em casa, na faculdade, nas relações com a família e com os amigos. Os operadores relatam que "demora muito para desligar", e por isso ficam "ligadões" e "irritados" mesmo depois de saírem do trabalho. A penosidade faz-se presente em todas as dimensões da vida do operador.

\section{Ações adaptativas: o trabalhador em busca de algum nível de controle}

Para que possam sobreviver à falta de controle sobre seu trabalho, constroem ações adaptativas, que buscam amenizar o sofrimento, o incômodo e os esforços no trabalho. Os operadores referem três tipos de ações adaptativas: a rotatividade, utilizar o recurso "mudo" do terminal telefônico (deixar que o cliente fale sem que o operador o ouça) e usar o recurso da "pausa".

Para Lúcia, o fato de sua atividade estar fortemente submetida à exigência de alcançar metas de venda, o tempo máximo suportável para permanecer no mesmo emprego era quase sempre o tempo mínimo de experiência: "se olhar minha carteira [de trabalho] não agüento mais de três, quatro meses, não agüento" (Lúcia). Para Pâmela, no entanto, o fato de ter a possibilidade de mudança de atividade, bem como a de exercer uma atividade considerada menos "estressante", faz com que esse período seja maior: "Dizem que o tempo máximo que um atendente pode ficar é dois anos mesmo, mas tem gente que já está há cinco anos, tem gente que chora até, tem dor de cabeça e tudo, minha amiga, ela não agüenta mais atender”. Porém, mesmo considerando-se tais variações, os entrevistados apontam que não é possível, para a maioria dos trabalhadores, trabalhar muitos anos nessa atividade.

A rotatividade nem sempre aponta para a busca de melhores condições de trabalho e de melhores salários, mas para a busca de novidades, de novos desafios, de sair da monotonia, do "...falar todo dia aquelas mesmas coisas, de ter que acessar sempre o mesmo sistema todo dia" (Carlos), já que depois de um período curto de tempo, a repetição e a mecanização tomam conta do trabalhador.

A técnica de "colocar no mudo" é uma outra ação adaptativa criada pelos trabalhadores para suportar a rotina de trabalho. Diante de um cliente "chato", "mal educado", "impaciente" ou de uma situação estressante, os atendentes ativam a função "mudo" do fone de ouvido e deixam o cliente esbravejar sem que sejam incomodados com gritos e chateações. É o que lhes resta para suportar o insuportável.

Há também a "pausa", recurso utilizado para que os operadores possam resolver algum problema ou "respirar" um pouco enquanto o cliente aguarda na linha, porque, "é um telefonema atrás do outro e você não tem tempo de respirar" (Raquel). Esse recurso permite um certo alívio, a possibilidade de respirar um pouco antes de prosseguir. Porém, possibilidade aberta apenas em pouquíssimos contextos. Em uma central de atendimento em que há uma centena de atendentes e milhares de ligações, essa prática é, além de proibida, difícil de ser executada.

Outra maneira de suportar o sofrimento é a busca por culpados. Daniele Linhart aponta como uma das características da lógica do serviço de teleatendimento o fato de o cliente transformar-se em bode expiatório, para o qual são dirigidas todas as "frustrações ligadas às pressões no trabalho" (Linhart, 2006). 


\section{Motivando para agüentar}

Práticas muito bem aplicadas, na ótica capitalista e mercadológica, as políticas de recursos humanos baseiam-se na suposta necessidade que haveria hoje entre os trabalhadores de serem permanentemente motivados para o trabalho. Surgem duas perguntas: por que se motiva tanto? O que se quer produzir ou o que se quer esconder?

Deleuze (1992) reflete sobre a persistência, na atualidade, de uma forte necessidade de motivar os trabalhadores. Assim ele reflete: "Muitos jovens pedem estranhamente para serem motivados e solicitam novos estágios e formação permanente; cabe a eles descobrir a que estão sendo levados a servir, assim como seus antecessores descobriram, não sem dor, a finalidade das disciplinas" (p. 4). A seu ver, essa necessidade repousa em dois motivos: a eterna insatisfação - fruto da sociedade de controle, que gerou o homem endividado - e a ideologia que nos leva a servir entes abstratos e de difícil localização e que nos levam a perguntar: a quem servimos? Quem é o "grande irmão"? O quê leva o trabalho a ser estressante?

As empresas buscam de forma incessante aumentar a produtividade de seus trabalhadores, buscando sempre o máximo de cada um. Assim, um trabalho que é visto pelos próprios trabalhadores como repetitivo, monótono e cansativo, não parece ser estimulante per se. Com isso, a empresa vale-se de alternativas motivadoras extrínsecas ao trabalho, para que o teleatendente o faça da forma mais rentável. Assim “'campanhas motivacionais' contemplam o atendente com brindes e folgas e há estímulo à competitividade entre colegas, pois os programas de produtividade são calcados na individualização excessiva da produção" (Vilela \& Assunção, 2004, p. 1075).

$\mathrm{Na}$ empresa que visitamos, uma das formas adotadas para motivar os trabalhadores era realizar uma competição entres as células. Seria feito um sorteio entre os operadores da célula ganhadora, o prêmio era uma viagem com acompanhante para a Disney. No entanto, os trabalhadores acharam injusto o prêmio, pois só contemplaria um membro da equipe, e pediram que ele fosse dado em dinheiro e dividido por todos os operadores da célula.

A organização é configurada de modo que os trabalhadores fiquem ligados o máximo possível à tarefa de ser porta-voz: sempre há algo a fazer, como por exemplo, dar "carona" a novos operadores, participar dos treinamentos, atualizar-se sobre novos produtos e serviços na intranet da empresa. Nessa overdose de informações com as quais o operador tem de lidar, sobra pouco tempo para pensar no trabalho que se está realizando.

Para manter o ritmo frenético de produção, além de valer-se de métodos de motivação, a empresa cria uma ideologia que associa o trabalho a determinados valores que acabam por defini-lo. "Você tem que ter muita agilidade, ser ligado, lógico, cooperativo, tem que trabalhar em equipe... é um saco, tem sempre que procurar incentivar os outros" (Lúcia). Esses valores, ao serem intrincados, pela empresa, ao processo de trabalho, são dados como verdades e cabe ao trabalhador não os questionar, mas sim adequar-se a eles, já que não há espaço para refletir sobre o trabalho.

O trabalhador, isolado pelos mecanismos de controle impostos, vê-se na tarefa de garantir sua sobrevivência na empresa, de lutar por sua recompensa, pois caso não consiga, o "brinde", o "aumento no salário", a "promoção", outro irá conseguir. Aparentemente, a viabilidade de uma promoção, por exemplo, é bastante atrativa, mas o quadro que um outro entrevistado apresenta faz refletir sobre essa viabilidade. Ele fala da probabilidade de mudar de cargo: "...muito difícil. Porque, assim, imagine uma equipe de cento e vinte operadores de teleatendimento, o apoio era composto por nove pessoas. Então, era difícil" (Carlos). Essa realidade particular não difere muito da situação geral apresentada pelos outros entrevistados. Vendese o sonho da ascensão profissional, da possibilidade de carreira e o que se pede em troca é 
uma dedicação robótica e a adaptação cega às condições de trabalho. "Existe essa possibilidade. Você quer? Você vai ser analisado entre outros, você pode vir a ser, subir de cargo, de salário" (Lúcia).

No entanto, como o trabalhador ainda não é um "robô de sedução" (Linhart, 2006), essa troca que a empresa propõe ao trabalhador não vem sem custo, como pudemos ver ao longo deste artigo.

A empresa, ao ter consciência dos limites humanos, adota soluções pontuais para o problema: "sala de descompressão", "festinhas", "ginástica laboral". Todas aparecem nas entrevistas como formas de compensar o trabalhador. A "sala de descompressão" é representativa dessa lógica.

Pâmela diz que na empresa em que trabalhava havia a "sala de descompressão", onde se podia ir quando "tivesse um pico de estresse no atendimento, para você compensar...". Intermediada pelo atendimento psicológico, Pâmela conta que a sala era usada poucas vezes, apesar da grande quantidade de estresse na central de atendimento, "não era uma sala que se podia usar a qualquer momento".

O profissional psicólogo que intermediava o uso da sala não estava presente na central de atendimento para auxiliar os funcionários e fazer um atendimento de "urgência"; fazia seu trabalho e podia ser solicitado quando houvesse "algum problema". Uma dinâmica que impede a atenção e a discussão desse fator no ambiente de trabalho.

Tomada como exemplo, a sala é representativa de uma função ambivalente dessas estratégias que visam aplacar o sofrimento. Primeiro, essas estratégias adotadas pelas empresas têm a função de acolher, de alguma forma, o sofrimento causado e proporcionam um momento de descanso frente à rotina estressante. Assim, o trabalhador tem sua capacidade produtiva restituída. Segundo, essas estratégias, ao simplesmente aplacarem o sofrimento sem a possibilidade de atuar-se sobre suas causas, tornam-se uma forma de controle. A organização do trabalho não é pensada, o processo de formação do porta-voz não se altera, nada muda. O que é por natureza um espaço construído torna-se naturalizado e estático.

Nota-se que todas as atividades promovidas são voltadas para "amenizar" os efeitos da penosidade do trabalho (sala de descompressão, apoio "psicoterápico" emergencial, ginástica laboral, "animação cultural", gincanas e festas durante o expediente). Mais que isso, parece não haver espaço para discutir-se o trabalho, nem para propor uma política que busque a melhoria das condições do trabalho.

O trabalhador, dessa forma, é colocado sob a tutela da empresa, sem possibilidade de questionar o espaço no qual está inserido, tendo que se adaptar a todo custo. Caso a tutela não seja efetiva, o único culpado é ele mesmo, ou é o cliente, ou é o supervisor, mas nunca a lógica de trabalho que retira do trabalhador a possibilidade de assumir o controle de seu trabalho, que o trata como uma criança.

Com isso, essas práticas visam a manter apenas a saúde dos trabalhadores necessária à reprodução do capital, que venha tão somente a responder às necessidades gerenciais, sem que haja alterações profundas no processo de trabalho, mesmo que essas se façam necessárias.

Tais mudanças implicariam em uma reestruturação do jogo de poder dentro da organização, o que levaria ao questionamento de certezas já pré-estabelecidas e que são dadas como naturais. Tutelado e isolado, o trabalhador não consegue buscar forças por ver-se intricado dentro de uma organização na qual ele não pode ser um participante ativo.

Assim, com o passar do tempo, o trabalhador que não consegue adequar-se, não vê outra saída se não deixar o trabalho. O tempo necessário para que isso aconteça, segundo os entrevistados varia, mas dificilmente alguém fica mais de dois anos em uma mesma empresa, 
ainda que haja aqueles que construam carreira no setor ou que nele trabalhem há muitos anos como atendentes.

\section{Discussão}

Através do caminho de pesquisa para conhecer a área de teleatendimento, fomos aproximando-nos sucessivamente do trabalho de atendimento e descobrindo uma vasta e profunda área que antes parecia-nos nebulosa.

Do sítio de relacionamentos Orkut à visita e, por fim, às entrevistas, fomos adentrando esse universo, mais especificamente, o do operador de teleatendimento. A partir desse ator, que nos serviu de guia, pudemos cartografar esse campo de trabalho, principalmente em sua dimensão subjetiva.

No caminho, deparamo-nos com as dimensões do tempo e do controle e vimos o quanto essas dimensões eram centrais - não obstante, objeto de disputa constante por parte do trabalhador - na relação entre trabalho e saúde para o operador. No decorrer da pesquisa observamos o que significa "viver na baia".

A baia não se restringe apenas ao limite físico do espaço onde o operador trabalha, ela estende-se a toda uma lógica disciplinar presente que restringe ao máximo o espectro de liberdade de atuação - conseqüentemente possibilidade de controle sobre o próprio trabalho - do operador. A baia é a rotina maçante de trabalho, é o script que limita a fala do operador, é a constante estimulação a que o operador está sujeito, é a falta de perspectiva de poder ter um cargo mais alto na hierarquia, é ser constantemente vigiado. Desse modo, a baia isola o trabalhador tanto na dimensão temporal, quanto nas dimensões espacial e social.

"Viver na baia" é, sobretudo, isolar-se e experimentar possibilidades restritas de construir laços de amizade e de ajuda. Tal vivência não é experienciada sem uma grande carga de sofrimento.

Visto isso e apesar de toda a evolução tecnológica, não é surpreendente o fato de o trabalho no teleatendimento, em 2006, ter feições e repercussões para a saúde tão próximas às descritas por Le Guillant e seus colaboradores, em 1956, para as telefonistas.

A "atomização" (Linhart, 2006) faz parte da lógica do poder e do controle organizacional, mas quando o desenho organizacional assim possibilita, a solidariedade e a ajuda mútua entre os operadores possibilitam aliviar o sofrimento e resolver problemas do trabalho, como mostra a operadora Raquel. Trabalhando em contexto distinto dos outros, ela experimentou situação de trabalho submetida a menor pressão e mostra que muitas conversas com os colegas durante o expediente são trabalho e não "perda de tempo", como suporia a perspectiva gerencial.

"Dentro do script, pode fazer tudo" (Pâmela), uma frase irônica que resume a impossibilidade de se mover no trabalho. Os operadores estão presos na baia, tendo como horizonte carregar a pedra de Sísifo.

A análise do anexo II da Norma Regulamentadora 17 (portaria no 153 de 14 de março de 2006, da Secretaria de Inspeção do Trabalho, Ministério do Trabalho e Emprego) faz-nos pensar, e constatar, que não há dúvidas sobre as péssimas condições de trabalho a que estão submetidos os operadores que vivem na baia.

Quando o trabalhador consegue uma brecha nos limites da baia, ele encontra alívio e uma maneira diferente de experienciar o seu trabalho. No entanto, enquanto a "baia" for intransponível, o verbo "agüentar" continuará sendo muito utilizado, evidenciando o peso de 
um trabalho que ultrapassa os limites do suportável e, quando não for mais possível agüentar, os operadores buscarão caminhos para não enlouquecer, como diz Carlos: "quer saber, ou eu faço alguma coisa da minha vida ou eu vou ficar louco trabalhando, é o que eu não quis, aí eu peguei e acabei saindo de lá".

O que pudemos identificar, como única característica positiva, não só nas entrevistas, mas também no Orkut, foi que o trabalho em teleatendimento possibilita aos operadores sentirem-se mais hábeis para se comunicar depois de terem entrado nesse mercado.

Foi possível observar muito sobre o mundo do teleatendimento, mas muitas questões ficaram em aberto, como por exemplo, um ponto que foi levantado por um dos entrevistados sobre o fato de o teleatendimento ser ou não uma profissão. Além disso, vimos o teleatendimento por apenas uma perspectiva, sendo ainda possível vê-lo por outros ângulos diferentes, como por exemplo, o do cliente ou o do supervisor.

\section{Referências}

Dejours, C. (1986). Por um novo conceito de saúde. Revista Brasileira de Saúde Ocupacional, 54 (14), $7-11$.

Deleuze, G. (1992). Post-Scriptum sobre a sociedade de controle. In Conversações (pp. 219-226). Rio de Janeiro: Editora 34.

Fernandes, S. R. P., Di Pace, D. M. T. \& Passos, M. F. (2002). Organização e condições de trabalho em telemarketing: repercussões na saúde psíquica dos trabalhadores. In M. G. Jacques \& W. Codo (Orgs.), Saúde mental e trabalho: leituras (pp. 247-270). Petrópolis: Vozes.

Foucault, M. (1994). Vigiar e punir: nascimento da prisão. Petrópolis: Vozes.

Glina, D. M. R. \& Rocha, L. E. (2003). Exigências do trabalho, prevalência de dor muscular e de sintomas de estresse em estagiários do setor de cobrança de um banco internacional. Revista de Terapia Ocupacional, 14 (1), 10-18.

Le Guillant, L., Roelens, R., Bégoin, J., Béquart, P., Hamsen, M. \& Lebreton, F. (1984). A neurose das telefonistas. Revista Brasileira de Saúde ocupacional, 17 (47), 7-11.

Linhart, D. (2006). A caminho da desumanização. Le Monde Diplomatique (dossiê Futuro do Trabalho). Artigo disponível na Internet: http://diplo.uol.com.br/imprima1265 [22 março 2006]

Marx, K. (1980). Processo de trabalho e processo de produzir mais valia. In O capital: crítica da economia politica (livro I, volume I, 6⿳a ed., pp. 201-223). Rio de Janeiro: Civilização Brasileira.

Nogueira, C. M. (2006). O trabalho duplicado - a divisão sexual no trabalho e na reprodução: um estudo dos trabalhadores do telemarketing. São Paulo: Expressão Popular.

Oliveira, S. de (2005). Políticas de gestão e saúde em teleatendimento: das telefonistas aos teleoperadores. Dissertação de Mestrado, Instituto de Psicologia, Universidade do Rio Grande do Sul, Porto Alegre.

Ministério do Trabalho e Emprego (2006). Anexo II da Norma Regulamentadora 17 (portaria no 153 de 14 de março de 2006).

Sato, L. (1993). A representação social do trabalho penoso. In M. J. P. Spink (Org.), O conhecimento no cotidiano: as representações sociais na perspectiva da psicologia social (pp. 188-211). São Paulo: Brasiliense.

Thompson, E. P. (1998). Tempo, disciplina do trabalho e o capitalismo industrial. In Costumes em comum (pp.267-304). São Paulo: Companhia das Letras.

Venco, S. (2003). Telemarketing nos bancos: o emprego que desemprega. Campinas: Unicamp. 
Vilela, L. V. O. \& Assunção, A. A. (2004). Os mecanismos de controle da atividade no setor de teleatendimento e as queixas de cansaço e esgotamento dos trabalhadores. Cadernos de Saúde Pública, 20 (4), 1069-1078.

\section{Endereço para correspondência}

carolramalho@yahoo.com.br

Recebido em: 20/06/2007

Revisado em: 22/11/2007

Aprovado em: 17/04/2008 